\title{
Perceived Forms, Prevalence and Consequences of Gender Based Violence: The Case of Hawassa University Female Students
}

\author{
Adamu Assefa Mihrka ${ }^{1}$, Abebe Hailemariam Lembeme ${ }^{2}$ \\ ${ }^{I}$ (Department of Psychology, College of Social Sciences and Humanities, Hawassa University, Ethiopia) \\ 2(Department of Biology, College of Natural and Computational Sciences, Hawassa University, Ethiopia)
}

\begin{abstract}
This study aims to assess the prevalence and types of gender based violence at the five campuses of Hawassa University among female students. Using self administered questionnaires and structured interviews, and focused group discussions we determined the prevalence and types of gender based violence at the 5 campuses. The data obtained from the questioners was analyzed using soft ware statistical package of SPSS and the significance tests were carried out using Chi-square test. The most frequently observed violence in the campuses were pushing or tripping; grabbing breasts, buttocks and pinching; offensive verbal and sexual comments; and twisting earlobes and pilling hair. Compared with teachers and administrative workers of the university, male students had committed gender based violence in a greater proportion. The study also revealed measures taken by the university on perpetrators to mitigate the problem and help survivors were not sufficient and effective. Even though, female students of the university have good perception towards gender based violence, most of their responses towards gender based violence were ineffective. Based on the findings it is recommended that the university has to develop (adopt) clear policy on sexual harassment and clearly communicate it to the students, academic staff, and office workers every year. In addition, the university should including strict rules and explicit penalty/sanction statement for each kind of violence in the policy.
\end{abstract}

Keywords: Gender based violence, Violence, Girls, Female Students, Campuses, University

\section{Introduction}

Gender-based violence (GBV) has been defined by $\mathrm{CEDAW}^{1}$ committee as violence that is directed at a person on the basis of gender or sex. It involves conducts that cause physical, mental or sexual injury, intimidation of such conducts and other deprive the person's freedom. Even though the concept of GBV implies both gender groups, the study emphasizes only the female gender group because GBV is manifested in Ethiopia particularly against women and girls.

GBV has been increasingly recognized around the world as a grave challenge for public health and development and as a violation of human rights. In Africa, as in other regions, GBV perpetrated against women and it is an extremely complex issue resulting from and perpetuated by various societal, economic and cultural factors. When different groups of women have collected attention and energy for action, a wide range of initiatives across the region have exerted their powers towards mitigating, preventing and responding to such violence (1).

The issue of GBV is currently the burning and contemporary issue of our country as well as the problem of most developing countries. The problem is supposed to be significant because the violence is becoming serious from time to time and taking place in coincidence with an increased risk of HIV infections. Students in different institutions were conducted predominantly on young adults between the ages of 18 and 25 years (2).

Similarly, GBV has been a growing concern for a long time now in Ethiopia. It has mostly affected women and girls making it very difficult for them to participate in developmental activities at family, school and community levels. GBV is becoming one of the most triggering issues in the face of the spread of HIV infections throughout the country on one hand and the physical, social and psychopathological impact on the other.

While violence against women has become an international public health and human rights issue over the past decades, but it is only in recent years that the incidence of such violence in formal schooling has been explored (3).

Primarily, GBV is a recurrent problem especially in higher education institutions and universities and is reported to cause social and academic problems to female students demanding immediate interventions to overcome the challenge (4). Likewise, the researchers had observations of the occurrences of GBV among the

\footnotetext{
${ }^{1}$ Convections on the Eliminations of Discriminations against Women
} 
campus girls which could considerably hindered the process of their education in the university and more specifically would have an adverse effect on their academic performances. The hunch was the appeal and report of female students to their respective colleges and departments on the issue of sexual harassment and violence in and out of classroom situations. In addition, circumstantial evidences that have been gathered from the meetings held in 1913/14 academic year with female students of the College of Natural and Computational Sciences (CNCS) have shown the status of occurrence of GBV in the Main Campus. During that time, among the cases which were reported to CNCS and to the department of Biology, nearly $70 \%$ of the college female students were biology majors.

Furthermore, the education and training of students in the country take place in multi-cultural and multiethnic environments where students gathered from different social, economic, gender, and religious backgrounds. This fact affects the knowledge, expectations, attitudes, behavior, emotional and social intelligence of the students. Consequently, campuses tend to be male dominated creating male tolerant cultures and environments. Economic problems also exert enormous pressures on students making them violent or docile in the face of social challenges. These factors combine to make tertiary institutions sources of deviant gender behavior with females mostly, but not exclusively, at the receiving end. Such behavioral patterns include sexual harassment and other acts of GBV. The outcome of these may include a feeling of insecurity, particularly among female students thereby discouraging them from enrolling in higher institutions and further accentuating the skewed student population in favor of males. Hence, school-related GBV represents a serious obstacle to learning causing not only physical harm but also severe psychological and educational adverse consequences (5).

With the intention of assessing perceived forms, prevalence and consequences of GBV among girls in Hawassa University as its general objective, the study was further designed to achieve the following specific objectives: Therefore, the study has

$>$ Identified the university female students' perceptions about GBV.

$>$ Identified the types of GBV in the campuses of the university.

$>$ Identified the extent of GBV in the university.

$>$ Investigated the common perpetrators of GBV in the university.

$>$ Identified the consequences and implications of GBV on female students in the university.

$>$ Explored measures taken by the survivors, university administration and legal institutions.

D Identified whether the University campuses were safe with respect to GBV the factors that expose girls for GBV in the campuses.

$>$ Recommended intervention strategies to minimize the problems.

\subsection{Types of Sexual and GBV}

GBV continues to be a significant and serious human rights and public health issue. It is an issue that disproportionately affects women and girls of all ages, from all cultures and socio-economic backgrounds. According to Tesemma (6), GBV takes many forms, including rape, domestic violence, forced marriage, exploitation and harassment, sexual violence and female genital mutilation. It impacts the physical, emotional, psychological and social well-being of women and girls.

The prevalence of GBV, including domestic abuse, harmful traditional practices (HTP) and general negative perceptions, attitudes and beliefs about women and their abilities and roles around throughout Ethiopia. Over the past few years, the Government of Ethiopia has issued a relatively large amount of gender-friendly legislation and policies, including the 'National Women's Policy', which was issued in 1993 (7). This was based on the concept of respect for human and democratic rights without distinction, as set forth in the Charter on International Agreements and Conventions. Despite this case, as well as other legislative acts, judicial and educational policies and efforts to address the situation by government agencies, nongovernmental organizations and civil society organizations, clearly, women remain highly vulnerable in Ethiopia and continue to suffer from violence and denial of their rights in one form or another.

The Centers for Disease Control and Prevention [CDCP] (8) identifies violence against women as a broad category encompassing "intimate partner violence, sexual violence, and other forms of violence against women committed by acquaintances or strangers." Within the category of intimate partner violence, the CDCP includes physical violence, sexual violence, emotional abuse, and threats. Such violence against women is a serious and pervasive public health problem.

GBV is a cross-cutting and complex phenomenon that should be addressed at all levels and by all stakeholders (victims and their families, communities, institutions, cultural and religious leaders, educational institutions and perpetrators). Reversing the trends of the past several decades will not happen quickly, and creating the conditions for gender balance and a respect for human rights in general is of critical importance. A broad based approach will be necessary, in which a focus is given to awareness raising, capacity building, improved policies, prioritization and utilization of resources with a multiple and flexible strategies. The 
approach must seek to change societal values, attitudes and behaviors that condone or encourage GBV, and target perpetrators as well as families and other members of society (6).

\subsection{The Extent and Prevalence of GBV}

The most pervasive form of GBV is abuse of women by intimate male partners. A recent review of 50 population-based studies carried out in 36 countries indicates that between 10 and 60 per cent of women who have ever been married or partnered have experienced at least one incident of physical violence from a current or former intimate partner (9). Although women can also be violent and abuse exists in some same-sex relationships, the vast majority of partner abuse is perpetrated by men against their female partners. Violence against women is a rampant human right violation in almost all countries of the world. In this regard USAID (10) reported that sexual violence against girls in schools is a serious problem in many African countries. Moreover a study conducted by Save the Children (11), in Africa, Asia and Latin America showed that in all countries sexual abuse of girls and boys takes place in all settings, where both girls and boys are sexually abused and exploited. As a rule, girls are most at risk and the perpetrators are mostly males.

In Ethiopia, GBV occurs in the pretext of tradition and culture and is condoned by the society at large. It appears to be accepted as part of daily life, and the existing laws and policies have done little to the address the issue. Ethiopia has one of the highest reports in the world in physical assault by male partners (12).

\subsection{Prevalence of GBV in Schools and Universities}

Violence among young people is increasing dramatically in face of $21^{\text {st }}$ century. Perhaps what is not alarming is that these violent acts are not only occurring on the streets, in broad day light, but in the school system as well. Wood (13) defines school violence as any physical and verbal attack on a person while on school grounds or on school property. We will stick to this ground because the present study refers to violence against women or girls because it involves in part from the women's subordinate gender status in society.

In an educational setting in Ecuador, 22 percent of the adolescent girls reported being victims of sexual abuse (14). A qualitative study in Addis Ababa, Ethiopia found that bullying and attempted rape were factors in low female enrollment rates and high dropout rates from secondary schools (15). There was public awareness and concern about this, but many families and schools felt helpless to bring about change. Both male and female respondents in this study identified girls' general behavior as a cause of the bullying and sexual violence.

Studies conducted in the university of Northern Nigeria (5), showed that overall, 171 of the respondents (out of 300) admitted having ever experienced one or more forms of GBV since joining the university. Of the students who experienced violence, $22.8 \%$ experienced physical violence, $22.2 \%$ reported sexual violence and $50.8 \%$ endured emotional and verbal violence. In another study conducted in Mekelle, Ethiopia, $32.3 \%$ of the students reported experiencing at least one form of physical violence since joining college. Elsewhere, in Chile, a similar proportion (21\%) of college students reported at least one episode of physical violence by boyfriends. These differences could be due to differences in cultural characteristics of the study populations, drug and substance abuse in schools and the misuse of the internet in sharing information about dating culture and violence across the globe (4).

Male students were the main offenders in most cases of all three forms of violence, while lecturers were only implicated in emotional violence. This is the case with some studies on violence against girls in schools. For instance, in South Africa, both male students and teachers were complicit in the harassment and abuse of female students. Studies in Zimbabwe, Ghana and Malawi, reported that older male students and teachers as perpetrators of sexual violence (5). Recent information on sexual harassment in higher educational institutions indicated that female students are not only perpetrated by male students only, but also by some unethical instructors and administrative workers of universities (16).

A study on GBV in Sierra Leone showed that $27 \%$ of students reported that their teachers and lecturers were the perpetrators (17). In a study carried out in Yaoundé, Cameroon, 30\% of the GBV were perpetrated by classmates or other school friends of the victims and about $8 \%$ by teachers, family friends, neighbors, and strangers (18). In another study of 10,000 girls in sub-Saharan Africa, it was found that the majority of the perpetrators of sexual violence were male students (19). The non-involvement of lecturers in the present study may be real or a case of underreporting. A cross-sectional study on prevalence of GBV in three high schools of Addis Ababa, Ethiopia by (20) revealed $75.9 \%$ of the students reported being sexually harassed, showing that it was a significant public health problem which should be given great emphasis of social support and law enforcement to mitigate the challenge.

\subsection{The Consequences and Implications of GBV}

GBV includes a lot of harmful behaviors that are directed at women and girls because of their sex, including wife abuse, sexual assault, and dowry-related murder, and marital rape, selective malnourishment of female children, forced prostitution, female genital mutilation, and sexual abuse of female children. Specifically, 
violence against women includes any act of verbal or physical force, coercion or life-threatening deprivation, directed at an individual woman or girl that causes physical or psychological harm, humiliation or arbitrary deprivation of liberty and that perpetuates female subordination (9). In developing countries, the problem is particularly severe because the violence is, at times, extreme and takes place in conjunction with an increased risk of health problems.

GBV in developing countries is acute problem because it is related with HIV infections especially in the countries where the infection rate is high. According to the report of USAID (2003), the consequences of GBV is absenteeism, grade repetition, dropout of school, negative and confused believes of self, exposure to sexually transmitting infections and unwanted pregnancy. The documented consequences of physical, emotional and sexual violence on women's health include chronic pain, injury, depression and suicide, and increased risk of reproductive health problems and adverse pregnancy outcomes (21). Women and girls are more vulnerable to HIV infection because their lower social status and disadvantages related to health care access, education and employment. It was evident from the study conducted by Muireann and Allen (22) in Tigray, Ethiopia that GBV causes different types of effects but primarily the effects were related with poverty, physical effects, emotional or psychological and educational.

\subsection{Legislative endeavors Taken at State and Institution Levels to Mitigate GBV}

In the continent different countries recently started to take a lead in developing policy on GBV which is supposed to help to increase peoples' awareness on the issue and governments' initiatives in showing their willingness to get rid of GBV. The Gambian government introduced a sexual harassment policy for schools in response to high rate of sexual violence (23). On July 17, 2006, the Republic of Benin's National Assembly endorsed the first wide-ranging sexual harassment legislation that would be supposed to protect girls and women in schools, workplaces and in homes (24).

At federal level, the Gender Mainstreaming Unit of the Ministry of Education (25) developed a guideline which consists of programs and rules to prohibit GBV in the educational settings. Currently the Ethiopian MOE had produced a working guide line to prohibit GBV and related issues as observed in the Gender Directorate of Hawassa University. However, those guidelines were not well developed into formal legislation by specifying every detail of definitions, sanctions related to each kind of violence, background for defense of unfair charges; and not openly disseminated to the university community for awareness and law enforcement.

This guideline stated actions to be taken on individuals/groups who committed such violence in schools are the following:

1. The one who insult and ashamed female students for three consecutive times and not in a position to correct the conduct will be suspended from the school for one year.

2. The one who fight and attempted to fight female students will be suspended from school for two years. Upon completion of his suspension he is allowed to the school by the recommendation of parent-teacher associations or concerned bodies of the institution about his change of behavior.

3. The one who raped female student will be dismissed from the school/institution for once and for all.

At institution level, it is crucial that colleges and universities have to develop a sort polices for the sake of preventing sexual harassment and to increase awareness for those who are involved in such activities. In this regard, the university stated different articles in the academic legislation (26) which define the act of sexual harassment and the charges associated with such conducts. But as Kelly (27) pointed out, such kinds of policy guidelines are one directional and usually focus on the risk that one party, usually the student, will become hurt in some way by the relationship and bring some sort of charges against the other party. Such kind policies lack a strategy which could entertain a grievance raised by individuals who feel unfair accusations and demand an opportunity for defense.

\section{Methodology}

The study employed the descriptive survey design. The instruments were questionnaire, interview and focus group discussion (FGD) with the aim of gathering both quantitative and qualitative data.

From 2608 total female population of Hawassa University, 260 female students (10\%) filled out the questionnaire and 12 students were participated in the FGD. In addition, relevant information was also collected from key informants including Student Service Affairs, Student Council, Gender Mainstreaming Directorate/Unit and University Police offices by using interview. The participants were from second and third year regular students of the five campuses (Main, Medical, Agricultural, Wondogent and Awada). For the purpose of maintaining representativeness of the sample, students were selected proportionally from each campus (stratum). The sampling technique within the stratum was that of availability with their consent to participate in the survey. 
The data on types and prevalence of GBV was statistically computed by using percentage. The significance of these statistical measures was tested through Chi-square test. The data from the questionnaires was manipulated by computer software - Statistical Package for Social Sciences (SPSS). The data gathered from the FGD and interviews were qualitatively analyzed through narration method.

\subsection{The Descriptive Characteristics of the Respondents}

\section{Results and Discussions}

As Table 1 indicates, all the respondents were female students from the five campuses of Hawassa University. The questionnaires were distributed to 260 respondents, but properly filled and returned were 243 (137 from second year and 106 from third year students). That is, the response rate was $93 \%$.

Table 1: Descriptive Statistics of the Campuses and Students' Duration

\begin{tabular}{|l|r|}
\hline Campuses & Frequency \\
\hline Main Campus & 98 \\
\hline Agriculture & 44 \\
\hline College of Medicine and Health Sciences & 37 \\
\hline Wondogenet College of Forestry and Natural Resource & 29 \\
\hline Awada College of Business and Economics & 35 \\
\hline Total & $\mathbf{2 4 3}$ \\
\hline Duration & 137 \\
\hline Year 2 & 106 \\
\hline Year 3 & $\mathbf{2 4 3}$ \\
\hline Total & \\
\hline
\end{tabular}

\subsection{Students' Perception on GBV}

To identify the students' perception on GBV, their responses on 14-item rating scale questionnaire were analyzed and presented on Table 2.

Table 2: Chi-Square Test among the Three Categories of Responses of Hawassa University Female Students about the Perceptions on Different Aspects of Gender Based Violence

\begin{tabular}{|c|c|c|c|c|c|c|c|c|}
\hline & & & Observe & & & & & \\
\hline & & Agree & Disagree & Undecided & Expected & $\chi^{2}$ & df & $\mathrm{p}$ \\
\hline 1 & Male teachers have a right to request girls for sexual intercourse & 28 & 199 & 14 & 80.3 & 264.158 & 2 & 0.000 \\
\hline 2 & Male students have a right to request girls for sexual intercourse & 24 & 204 & 13 & 80.3 & 286.315 & 2 & 0.000 \\
\hline 3 & Girls have a right to say no for sexual intercourse & 221 & 15 & 6 & 80.3 & 366.702 & 2 & 0.000 \\
\hline 4 & Teachers have responsibility to protect students' security & 226 & 14 & 2 & 80.3 & $393.653^{\mathrm{a}}$ & 2 & 0.000 \\
\hline 5 & $\begin{array}{l}\text { Teachers can protect students' security by collaboration with parents and } \\
\text { other responsible bodies }\end{array}$ & 202 & 17 & 22 & 80.3 & 276.556 & 2 & 0.000 \\
\hline 6 & It is possible to punish girls and boys by heavy work & 11 & 218 & 12 & 80.3 & 353.884 & 2 & 0.000 \\
\hline 7 & $\begin{array}{l}\text { Sometime boys can punish by slapping of biting girls when they exhibit } \\
\text { unwanted behavior }\end{array}$ & 13 & 216 & 12 & 80.3 & 343.676 & 2 & 0.000 \\
\hline 8 & $\begin{array}{l}\text { It is possible to students to call on another with nick names, it doesn't } \\
\text { hurt }\end{array}$ & 73 & 100 & 68 & 80.3 & 7.378 & 2 & 0.000 \\
\hline 9 & Teachers can call students with nick names, it doesn't hurt & 44 & 140 & 57 & 80.3 & 67.527 & 2 & 0.000 \\
\hline 10 & Boys or girls have a right to agree or disagree to converse with others & 191 & 29 & 22 & 80.3 & 226.669 & 2 & 0.000 \\
\hline 11 & If girls get intimidated with sexual harassment, it is girls own mistake & 29 & 190 & 21 & 80.3 & 227.275 & 2 & 0.000 \\
\hline 12 & $\begin{array}{l}\text { Girls enjoy when getting touched breasts and other sensitive body parts } \\
\text { even without their consent }\end{array}$ & 25 & 159 & 56 & 80.3 & 123.025 & 2 & 0.000 \\
\hline 13 & $\begin{array}{l}\text { So far a teacher is going to marry a girl, sexual relation with student is } \\
\text { not prohibited }\end{array}$ & 71 & 112 & 58 & 80.3 & 19.776 & 2 & 0.000 \\
\hline 14 & A teacher who has sexual relation with girls should be dismissed & 84 & 88 & 69 & 80.3 & 2.498 & 2 & 0.287 \\
\hline
\end{tabular}

a. 0 cells $(.0 \%)$ have expected frequencies less than 5 . The minimum expected cell frequency is 80.3 .

As indicated in the Table 2, the three categories (agree, disagree, and undecided) were significantly different at $\chi^{2}$ between the lower 7.378 and the higher 393.653, $p<.000$ for the first 13 items. That is, very high proportion of girls showed their agreement for the questions that state their right (item number 3, 4, 5, and 10) and similarly very high proportion of girls indicated their disagreement for the questions that contain the violation of their gender and human rights (item number 1, 2, 6, 7, 8, 9, 11 and 12). From this we can come to agreement that Hawassa University students who are at different years and departments have clear perception on the GBV. Regarding the last question, there were no significant difference among the three categories (agree, disagree, and undecided) at $\chi^{2}=2.498, \mathrm{p}>.287$. This indicates that it was difficult to come to conclusion about 
the actions to be taken upon teachers who have sexual relations with students. This shows students' position on taking punitive measure on perpetrators on their first mistake. Girls have a conviction that the University or any organization should first prepare law before taking any kind of mitigating measures upon the perpetrators.

\subsection{The Types and Extent of GBV Perpetrated in the University Campuses}

Table 3: Types and Prevalence of Physical and Sexual Violence Committed for the Last 2 Years

\begin{tabular}{|l|r|r|}
\hline Types of physical and sexual violence & Incidents & Per cent \\
\hline Beating/Physical punishment & 7 & 7.95 \\
\hline Pinching, twisting earlobes, pilling hair & 14 & 15.91 \\
\hline Intimidating using weapons & 4 & 4.55 \\
\hline Whipping & 2 & 2.27 \\
\hline Pushing or tripping & 22 & 25.00 \\
\hline Raping without intimidating by weapon & 1 & 1.14 \\
\hline Forcing a girl to engage in sexual relation in favor of gift & 2 & 2.27 \\
\hline Undressing and let a girl be necked with force & 2 & 2.27 \\
\hline Grabbing breasts and buttocks & 19 & 21.59 \\
\hline Offensive verbal and sexual comments & 14 & 15.91 \\
\hline $\begin{array}{l}\text { Enforcing girls to watch pornographic pictures, cartoons or } \\
\text { other sexual material }\end{array}$ & 1 & 1.14 \\
\hline
\end{tabular}

As Table 3 revealed, the most frequently observed violence in the campuses were pushing or tripping (25\%); grabbing breasts and/or buttocks (21.59\%); pinching, twisting earlobes, pilling hair (15.91); and offensive verbal and sexual comments (15.91). Most respondents did not experience rape victimization. But, about 1 per cent of female students had been raped; almost 1.14 per cent of girls had been enforced by someone to watch pornographic pictures, cartoons or other sexual material; and 2.27 per cent were compelled to stand naked without their consent. Similarly, the interview and FGD results corresponds with the quantitative results in that the dominant forms of GBV were insulting, intimidation, physical and verbal abuses, humiliation and even sexual harassment.

Regarding the extent, the most prevailing GBV in the university were physical violence (including pushing or tripping; grabbing breasts and buttocks and pinching, twisting earlobes, pilling hair). The second common type was emotional and verbal violence (including offensive verbal and sexual comments. This finding goes with that of the study conducted in the university of Northern Nigeria (5). The study investigated that $22.8 \%$ of students experienced physical violence, $22.2 \%$ sexual violence and $50.8 \%$ endured emotional and verbal violence. On the contrary, in the case of a study conducted at 3 high schools of Addis Ababa (20) sexual harassment was very high $75.9 \%$, however, sexual violence was very low in the case of this study.

\subsection{The Common Perpetrators of GBV in the University}

Table 4: Identity of the Perpetrators in the Campuses

\begin{tabular}{|l|r|r|}
\hline Perpetrator & Frequency & Per cent \\
\hline Students & 74 & 83.15 \\
\hline Teacher & 8 & 8.99 \\
\hline Unidentified person & 4 & 4.49 \\
\hline Police & 3 & 3.37 \\
\hline
\end{tabular}

As we can see from Table 4, the most prevailing bodies that perpetrated sexual violence on the university girls were mail students followed by teachers. The incidents of sexual violence committed by campus police and unknown persons were very rare.

Similarly, the interview and the FGD results substantiated the quantitative data. In all campuses the interviewees and the FGD participants confirmed that the perpetrators in all cases were male students; however there were cases of teachers and administrative workers especially in the Main, Wondogent and Agriculture campuses. This study is very similar with that of Teshome (16). She reported on sexual harassment in higher learning institutions' female students were perpetrated by male students and some unethical instructors and administrative workers of the universities. 
Perceived Forms, Prevalence and Consequences of Gender Based Violence: The Case of....

\subsection{The Consequences and Implications of GBV on Female Students in the University}

Table 5: Frequencies and Percentages of the Impacts of Gender Based Violence

\begin{tabular}{|l|l|r|r|}
\hline No & Consequences & Frequency & \multicolumn{1}{|c|}{ Percent } \\
\hline 1 & It caused me to hate males & 33 & 35.48 \\
\hline 2 & It caused me not to trust persons & 28 & 30.11 \\
\hline 3 & My learning interest decreased & 12 & 12.90 \\
\hline 4 & It caused me health problem & 6 & 6.45 \\
\hline 5 & People disrespected me & 10 & 10.75 \\
\hline 6 & It caused me to hate people in general & 1 & 1.08 \\
\hline 7 & It made me lonely & 1 & 1.08 \\
\hline 8 & I hate to study at library & 1 & 1.08 \\
\hline 9 & Not explained & 1 & 1.08 \\
\hline & Total & $\mathbf{9 3}$ & $\mathbf{1 0 0 . 0 0}$ \\
\hline
\end{tabular}

As indicated in Table 5, the result from structured questionnaire showed that the major impacts of the GBV among the university girls were psychological in nature. Due to sexual harassment girls developed suspicion towards other persons, hatred towards males and deserved disrespect from other persons. Loneliness, hatred towards others, rejection from others etc. would have devastating impact on their teaching-learning interaction, which in turn lead to low achievement. Even though it was not well explained by the participants, the health impacts were also among the major consequences of GBV.

\subsection{The Responses of the Survivors towards the GBV Acts}

Table 6: The Students' Response for Physical and Sexual Harassment

\begin{tabular}{|l|l|r|r|}
\hline No & Responses & Frequency & Per cent \\
\hline 1 & Advised him & 2 & 2.33 \\
\hline 2 & Annoyed & 3 & 3.49 \\
\hline 3 & Doing the same to him & 1 & 1.16 \\
\hline 4 & I accepted it & 1 & 1.16 \\
\hline 5 & I begged him & 2 & 2.33 \\
\hline 6 & I said no & 3 & 3.49 \\
\hline 7 & Insulted him & 20 & 23.26 \\
\hline 8 & Silence & 31 & 36.05 \\
\hline 9 & Report to the responsible person & 5 & 5.81 \\
\hline 10 & Weeping & 9 & 10.47 \\
\hline 11 & Changing place & 3 & 3.49 \\
\hline 12 & Yelling at him & 6 & 6.98 \\
\hline
\end{tabular}

As Table 6 showed, the most frequent responses of girls to the perpetrators were silence and insulting. On the second place, weeping was moderately responded by the girls. Yelling (shouting) at the perpetrator and reporting to the responsible persons/body were also observed at lower rate. However, most of the students' responses towards GBV were ineffective.

\subsection{Types of Measures Taken by the University}

Table 7: Types of Measures Taken by the University

\begin{tabular}{|l|l|l|}
\hline No & Types of interventions/measures taken & Frequency \\
\hline 1. & Suspending the perpetrators from their studies & 3 \\
\hline 2 & Verbal and written warnings & 4 \\
\hline 3. & Giving advice and requesting the perpetrators to ask excuses from the girls & 7 \\
\hline
\end{tabular}

Table 6 shows that the major measures that have been taken by the university were "giving advice and requesting the perpetrators to ask excuses from the victims" followed by "verbal and written warnings" and "suspending the perpetrators from their studies." As the interview and FGD results also revealed, the university has taken the prevention strategies such as a number of awareness creation programs such as life skills and assertive trainings were conducted.

Allegations of GBV on students were handled by the student discipline committee. While, the GBV allegation cases of teachers and office workers were handled by the academic vice president of the university and by an ad hoc committee established under this office for the purpose of investigation and decisions. 
Perceived Forms, Prevalence and Consequences of Gender Based Violence: The Case of....

\subsection{The Security of the University Campuses with Respect to GBV}

Table 8: Chi-Square Test between the Two Categories of Girls' Responses on the Security of the University Campuses in Relation to Sexual Violence

\begin{tabular}{|c|c|c|c|c|c|c|}
\hline \multicolumn{7}{|c|}{ Are the campus settings prone for sexual violence? } \\
\hline \multicolumn{4}{|c|}{$\begin{array}{ll}\text { Frequencies } \\
\end{array}$} & \multicolumn{3}{|l|}{ Test Statistics } \\
\hline Category & Observed N & Expected N & Residual & $\chi^{2}$ & df & $\mathrm{p}$ \\
\hline Yes & 161 & 121.5 & 39.5 & $25.683 \mathrm{a}$ & 1 & .000 \\
\hline No & 82 & 121.5 & -39.5 & & & \\
\hline & 243 & & & & & \\
\hline
\end{tabular}

a. 0 cells $(0.0 \%)$ have expected frequencies less than 5 . The minimum expected cell frequency is 121.5.

As indicated in the Table 8, the two categories (yes or no) were significantly different at $\chi^{2}=25.683, p$ $<.000$. That is, very high proportion of girls agreed that the university campuses were highly vulnerable to sexual violence. The reasons for their feelings were due to the prevailing GBV observed in the university campuses.

\subsection{The Major Actors who participated in the Intervention Strategies in the University}

Table 9: The Frequencies of Interventions Taken by Different Bodies in the University

\begin{tabular}{|l|l|l|}
\hline No & The participants of the interventions & Frequency \\
\hline 1 & Gender Directorate/Unit & 5 \\
\hline 2 & Student service/ Student Council & 4 \\
\hline 3 & Campus police & 3 \\
\hline 4 & Friends of the perpetrators & 2 \\
\hline
\end{tabular}

Most of the actors who played the intervention were various departments who were supposed to take responsibility of mitigating GBV; however the measures that were taken by those parts were not as such to the levels expected. But the external bodies did not get involved in the process of GBV intervention of the university.

\section{The Major Findings}

- Hawassa University female students have appropriate perception towards GBV.

- The research identified eleven different kinds of GBV from single to high occurrences were exhibited in the campuses.

- The most prevailing GBV in the university was physical violence followed by emotional and verbal violence.

- The most prevailing bodies that perpetrated sexual violence on the university girls were male students followed by teachers.

- The major impacts of the GBV among the university girls were psychological in nature (namely suspicion and hatred towards people especially towards males, disrespect and rejection from others, and loneliness).

- The above impacts are supposed to have educational and psychological implications by lowering their achievement and decreasing their psychological wellbeing.

\section{Conclusions}

- The study showed that the prevalence of GBV in the university was relatively high with respect to physical violence and harassment. Regarding sexual violence the incident was low. However, since GBV has psychological, social, academic and health impacts on female students, it requires immediate and strong response from the university.

- The majority of the perpetrators were male students and teachers. This section of the population is the most knowledgeable, so the university should enforce strict GBV law to mitigate it.

- The interventions taken by the survivors, and the university were not sufficient and effective. Students require continuous and intensive training at all levels to defend GBV effectively.

\section{Recommendations}

1. The university has to develop (adopt) clear policy on sexual harassment and clearly communicate it to the students, academic staff, and office workers every year.

2. Including strict rules and explicit penalty/sanction statement for each kind of violence in the policy.

3. Forming permanent Sexual Harassment Complaints Committee/Unit which would involve in investigation and take immediate and appropriate disciplinary action.

4. Program priorities. Giving priority to preventive strategies because they are the most effective ways of dealing with the problem. For instance, sensitization and training. 
5. Developing and implementing risk reduction and health promotion programs in order to make the campuses safer.

6. Developing effective readiness mechanisms (such as hotlines) and improved counseling services to victims of GBV.

\section{Acknowledgements}

Our gratitude goes to the Office of Vice President for Research and Technology Transfer of Hawassa University, RTTD of the university, NCSC research co-coordinator, Research participants, Student Service Affairs, Student Council Leaders, Gender Directorate/Unit, and Campus Police.

\section{References}

[1]. USAID, Strengthening Regional work on Gender Based Violence: A meeting of activists, practitioners and researchers from the Horn, East and Southern Africa, Kampala, Uganda Nov 8-9, 2006.

[2]. Working Group on Higher Education (WGHE)/Association of African University (AAU), Mainstreaming gender in higher education in Africa, Module 8, 2006, 2-5.

[3]. IGWG of USAID. Addressing gender-based violence through USAID's health programs: A guide for health sector program officers ( $2^{\text {nd }}$ Edition) (Washington D.C: IGWG, 2008).

[4]. Y. Gebreyohannes, Prevalence and factors related to GBV among female students of higher institutions in Mekele town, Tigray, Northern Ethiopia, MPH Thesis, Department of Community Health, Addis Ababa University, 2007.

[5]. Z. Iliyasu, I. S. Abubakar, M. H. Aliyu, H. S. Galadanc, and H. M. Salihu, Prevalence and Correlates of Gender-based Violence among Female University Students in Northern Nigeria, African Journal of Reproductive Health September 2011, 15(3), 2011, 111-119.

[6]. T. Tesemma,. The status of gender based violence and related services in four Woredas: Bahirdar, Buraue, Bako, and Gulele. (Addis Ababa: CARE Ethiopia and USAID, 2008).

[7]. Ethiopia, Office of the Prime Minister, Women's Affairs Sector, National policy on Ethiopian women (Addis Ababa: Transitional Government of Ethiopia, Office of the Prime Minister, Women's Affairs Sector, 1993).

[8]. Centers for Disease Control and Prevention [CDCP] (2007), National youth risk behaviour survey. http://www.cdc.gov/HealthyYouth/yrbs/index.htm Retrieved on June, 23, 2013

[9]. L. Heise, M. Ellsberg, and M. Gottmoeller, A global overview of gender-based violence, International Journal of Gynecology and Obstetrics, 78 Suppl., 2002, S5-S14.

[10]. USAID, Unsafe schools: A literature review of school related gender based violence in developing countries (Virginia: Wellesey Centers for Research on Women and Development and Training Services, Inc. North Fairfax Drive, Suit 215, 2003).

[11]. Save the Children, UN study on violence against children: Executive summary and main recommendations, $2005,22$.

[12]. National Committee on Harmful Traditional Practices in Ethiopia [NCTPE], Harmful traditional practices in Ethiopia (Addis Ababa: United printers, 2003).

[13]. W. Wood (2007), School violence essay, http://www.School Violence essays.htm. Retrieved on 2/9/2013.

[14]. A. Morrison, M. Ellsberg, and S. Bott, Addressing gender-based violence in the Latin American and Caribbean Region, A Critical Review of Interventions, World Bank Policy Research Working Paper 3438, 2004.

[15]. T. Dereje, and D. Mengistu, Violence in Ethiopian schools: A study of some schools in Addis Ababa. (Paris: UNESCO International Bureau of Education, 1997).

[16]. K. Teshome, Sexual harassment in higher institutions, Addis Zemen, April 28, 67(230), 2008, 13.

[17]. Y. Alexander 2010, Prevalence of gender based violence in northern Sierra Leone, Technical report series; Center for Accountability and the Rule of Law (CARL-SL), http://www.carl-sl.org/home/reports, Accessed on Wednesday, June 15, 2016.

[18]. D. M. Menick, Sexual abuse at schools in Cameroon: results of a survey-action program, in Yaounde, Med Trop (Mars), 62, 2002, 58-62.

[19]. F. Leach, V. Fiscian, E. Kadzamira, E. Lemani and P. Machakanja, An investigative study of the abuse of girls in African Schools (London: Policy Division of the Department for International Development, 2003).

[20]. G. Lelisa, and L. Yusuf, A cross sectional study on prevalence of GBV in three high schools, Addis Ababa, Ethiopia. Ethiopian Journal of Reproductive health, 2(1) 2008.

[21]. L. Heise, M. Ellsberg, and M. Gottemeller, Ending violence against women: Population reports. (Baltimore: Johns Hopkins University, 1999).

[22]. N. Muireann, and M. Allen, Summary report on women's experience of GBV in Tigray, Ethiopia, University College Dublin, School of Applied Social Sciences, Ireland 2012, 1-7.

[23]. UNICEF 2005, Mothers' zeal in the Gambia gets girls into school, http://www.unicef.org/girlseducation/index 27533.html, Accessed on Friday, June 28, 2013.

[24]. M. Amusa and N. Mowad 2006, Benin bans harassment; U.S. ignores workers' abuse, Women's ENews, July 29, http://womensenews.org/2006/07/benin-bans-harassment-us-ignores-workers-abusel, Accessed on Wednesday, June 15, 2016.

[25]. Ministry of Education [MOE], Guidelines and programs for regulating gender based curriculum to support students, unpublished document produced by gender unit in the MOE, 1996.

[26]. Hawassa University, Hawassa University: Senate Legislation, Codes of conduct and sexual harassment and abuse, Chapter 7, 2011, $160-169$.

[27]. G.F. Kelly, Sexuality today: The human perspective ( $7^{\text {th }}$ edition) (Boston: McGraw Hill Company, 2001). 